\title{
AN INJECTIVE PSEUDO-BCI ALGEBRA IS TRIVIAL
}

\author{
Grzegorz DyMeK \\ Institute of Mathematics and Computer Science \\ The John Paul II Catholic University of Lublin \\ Konstantynów 1H, 20-708 Lublin, Poland \\ e-mail: gdymek@o2.pl
}

\begin{abstract}
Injective pseudo-BCI algebras are studied. There is shown that the only injective pseudo-BCI algebra is the trivial one.
\end{abstract}

Keywords: pseudo-BCI algebra, injective pseudo-BCI algebra.

2010 Mathematics Subject Classification: 03G25, 06F35.

\section{REFERENCES}

[1] D. Buşneag, Categories of algebraic logic, Editura Academiei Romane, Bucharest, 2006.

[2] W.A. Dudek and Y.B. Jun, Pseudo-BCI algebras, East Asian Math. J. 24 (2008) 187-190.

[3] G. Dymek, p-semisimple pseudo-BCI-algebras, J. Mult.-Valued Logic Soft Comput. 19 (2012) 461-474.

[4] G. Dymek, Atoms and ideals of pseudo-BCI-algebras, Comment. Math. 52 (2012) 73-90.

[5] G. Dymek, On the category of pseudo-BCI-algebras, Demonstratio Math. 46 (2013) 631-644.

[6] G. Dymek, On compatible deductive systems of pseudo-BCI-algebras, J. Mult.-Valued Logic Soft Comput. 22 (2014) 167-187.

[7] S. Eilenberg and J.C. Moore, Foundations of relative homological algebra, Mem. Amer. Math. Soc., Vol. 55, 1965. 
[8] G. Georgescu and A. Iorgulescu, Pseudo-MV algebras: a noncommutative extension of $M V$-algebras, The Proceedings The Fourth International Symposium on Economic Informatics, INFOREC Printing House, Bucharest, Romania, May (1999), 961-968.

[9] G. Georgescu and A. Iorgulescu, Pseudo-BL algebras: a noncommutative extension of BL-algebras, Abstracts of The Fifth International Conference FSTA 2000, Slovakia, February 2000, 90-92.

[10] G. Georgescu and A. Iorgulescu, Pseudo-BCK algebras: an extension of $B C K$-algebras, Proceedings of DMTCS'01: Combinatorics, Computability and Logic, Springer, London, 2001, 97-114.

[11] Y. Imai and K. Iséki, On axiom systems of propositional calculi XIV, Proc. Japan Academy 42 (1966) 19-22.

doi:10.3792/pja/1195522169

[12] K. Iséki, An algebra related with a propositional calculus, Proc. Japan Acad. 42 (1966) 26-29.

doi:10.3792/pja/1195522171

Received 26 October 2017

Revised 7 June 2019

Accepted 25 June 2019 